\title{
The magic of light! An entertaining optics and photonics awareness program
}

Carlos Florensa, Míriam Martí, S. Chaitanya Kumar, Silvia Carrasco

Carlos Florensa, Míriam Martí, S. Chaitanya Kumar, Silvia Carrasco, "The magic of light! An entertaining optics and photonics awareness program," Proc. SPIE 9289, 12th Education and Training in Optics and Photonics Conference, 92892J (17 July 2014); doi: 10.1117/12.2070738

Event: 12th Education and Training in Optics and Photonics Conference, 2013, Porto, Portugal 


\title{
"The magic of light!" - An entertaining optics and photonics awareness program
}

\author{
Carlos Florensa, ${ }^{1}$ Míriam Martí, ${ }^{1}$ S. Chaitanya Kumar $^{1}$ and Silvia Carrasco ${ }^{1}$ \\ ${ }^{1}$ ICFO-Institut de Ciencies Fotoniques, Mediterranean Technology Park, 08860 Castelldefels
}

(Barcelona), Spain

\begin{abstract}
Illusionism provides a surprising and unforgettable way of explaining photonics to a wide audience. Imagine grabbing with your own hand an egg-sized photon with the same incredible properties as in a quantum computer! And what about touching the light beam which detects and removes diseased cells like in cutting edge medical prototypes? The art of magic allows promoting photonics, exploring advanced subjects in an understandable and palpable fashion that strongly inspires all ages.
\end{abstract}

Keywords: outreach, photonics, magic, informal optics education, entertainment, wide audience engaging talk

\section{INTRODUCTION}

There is an increasing gap between society and cutting-edge science. More precisely, in optics and photonics, some people either have heard little about the incredible uses of light or they believe lasers and alike are beyond their understanding and their everyday life. These feelings have to be overcome in order to promote photonics careers among young students or, in general terms, to keep society involved in this research, supporting it with their interest. Thus the challenge is to bring front-line research to the wide audience in the most attractive way.

To achieve this goal, an exciting awareness program has been developed, matching science and magic shows. Entertainment through illusionism is an incredibly powerful tool to transmit ideas and inspire all-ages minds. In particular, to explain in an appealing and surprising manner the wonders of photonics, magic fits accurately. The physics of light is sometimes difficult to grasp. It follows its own -not always intuitive- rules, defying some pre-assumed conceptions of our daily experience, just as illusionism. That is why both fields marry really well and together, as they attract and stimulate an extensive range of audiences.

The whole project has been designed and boosted from the Outreach-Knowledge and Technology Transfer Team (Outreach-KTT Team ${ }^{2}$ ) at ICFO-The Institute of Photonic Sciences. ${ }^{1}$ The whole team has widely collaborated in the building of this awareness program. Another key point to produce a sharp content for the illusions has been the constant support of the top leading scientists from ICFO. The result is a solid talk-show, which was performed at International Symposiums such as 50 Years of Nonlinear Optics International Symposiums -NLO50 ${ }^{3}$ and at conferences in science museums, such as Barcelona Science Museum (CosmoCaixa ${ }^{4}$ ) and The National Museum of Science and Technology of Catalonia $\left(\right.$ mNACTEC $\left.^{5}\right)$. One of the main targets are students. Promoting the learning of optics and photonics must be done in such a manner there is no time for boredom but only for interaction and amusement. This is exactly what is achieved through magic shows! Thus, the performances have been taken to places as the Faculty of Mathematics and Statistics -FME ${ }^{6}$ or a theater full of high-school pupils.

In this paper are described the building steps as well as the analysis of the obtained results and possible further expansions of the project.

Further author information: (Send correspondence to C.F.)

C.F.: E-mail: carlos.florensa@icfo.eu, Office Telephone: +34 935534113

12th Education and Training in Optics and Photonics Conference, edited by

Manuel F. P. C. Martins Costa, Mourad Zghal, Proc. of SPIE Vol. 9289, 92892J

(C) 2014 SPIE, OSA, IEEE, ICO · doi: 10.1117/12.2070738

Proc. of SPIE Vol. 9289 92892J-1 


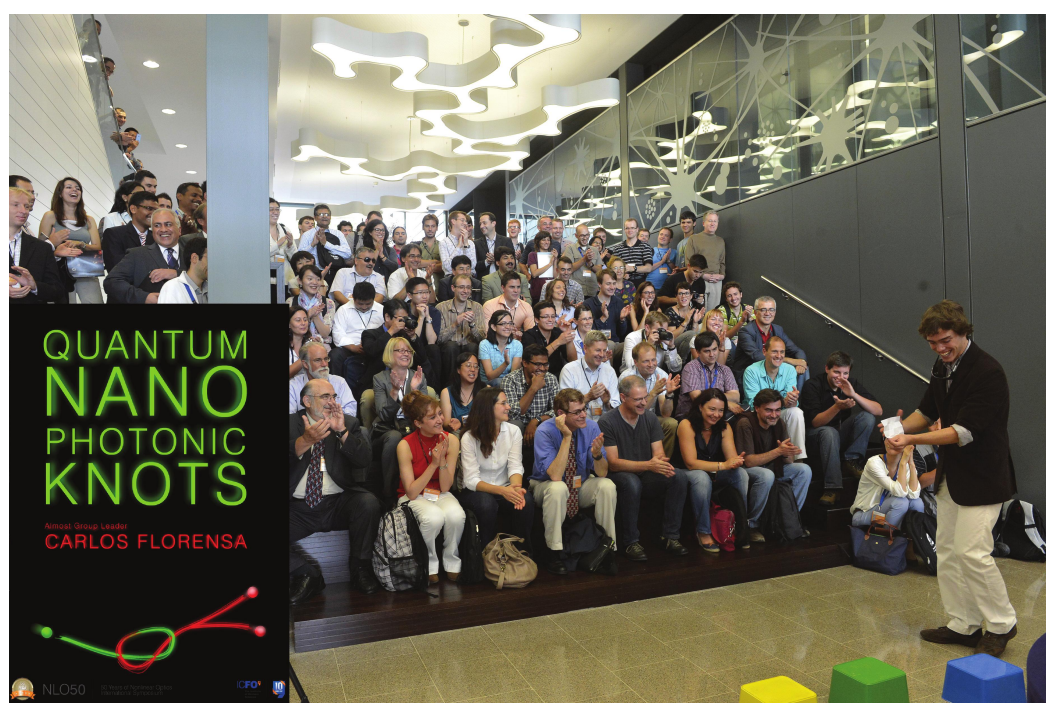

Figure 1. Performance for physicists during the NLO50. ${ }^{3}$

\section{AN EVOLVING PROJECT: FROM SCIENCE SYMPOSIUMS TO THE WIDE AUDIENCE.}

\subsection{The spark}

From the beginning, matching magic and science was orientated towards outreach activities. Nevertheless, in the preliminary stage of the project, it was designed to be included in science symposiums as $\mathrm{NLO}^{3}$ or congresses as Light for Health2012 -L4H. ${ }^{7}$ This conferred to the show an extra dose of scientific rigor that has been maintained throughout all subsequent transformations of the performance.

Primary objectives were to offer a fresh point of view without loss of accuracy and to relax a while in the middle of some tougher conferences. The performance could amaze and distract researchers, showing a funnier side of their science, and perhaps encouraging some to consider novel forms of presenting their activities. See Fig. 1.

Surrounded by an exigent audience, an effort was made to adapt or create magic tricks that could explain in a visual and surprising way the basis of Non-Linear Optics or Lasers for Medical Treatments. Through illusionism, it became straight forward to visualize two low-energy red photons generating their second harmonic green one! Just imagine two sponge balls vanishing in the performer's hands and letting place to a bigger one, all in front of the eyes of the public. Suddenly there is no longer need neither of mathematics nor momentum-balance equations to understand the concept behind NLO. Actually, some aspects of photonics almost resemble magic. And most of them are complicated to demonstrate in a way understandable for everybody, basically because it is complicated to handle real single photons and to see them in action. But here comes the bridge of magic tricks. Even Quantum effects can be shown with a deck of cards. The same for neurosurgery laser cutting illustrated with ropes.

Of course, the performances explained before do not enter in every detail of the physical process. It just scratches the surface giving the fundamental inputs to excite curiosity, to have fun with science, to inspire. And these attributes are the ones that propelled the project to the outreach world, incorporating a new dimension to the performances. Some feedback as the one provided by Dr. Tayyaba Hasan, Professor at Harvard Medical School "It was one of the best outreach acts I have seen. Very effective and educational," encouraged even more the spread of the show.

\subsection{The spread}

The potential of illusionism as a tool to transfer not only knowledge but also inspiration about science to the wide audience imposed the desired drift towards non-scientific public. The first trials where done with people 


\begin{tabular}{|l|r|}
\hline Welcome Catering & 7.55 \\
\hline Picnic at the beach & 7.1 \\
\hline Wok del mar & 9 \\
\hline Catamaran-Paddle surf-kayak & 7.14 \\
\hline Burguer Restaurant & 8.48 \\
\hline Comida UPC & 7.81 \\
\hline Dinner100 montaditos & 8.67 \\
\hline Breaks & 8.77 \\
\hline Welcome Miriam Marti & 8.89 \\
\hline Toni Acin: Quantum & 8.64 \\
\hline Darrick Chang: Quantum & 7.36 \\
\hline Carlos Florensa: Magic & 9 \\
\hline Marina Mariano: Basic Optics & 7.82 \\
\hline Valeria Rodriguez: Geometrical Optics & 7.3 \\
\hline Morgan Mitchell: Quantum & 7.1 \\
\hline LabTour: Belen & 8.62 \\
\hline Roberto Leon: Interference & 8.38 \\
\hline Yannick de Icaza y Venkata Badarla: & 8.4 \\
\hline Polarization & 8.72 \\
\hline Esteban Bermudez: Lab Activity 1 & 8.44 \\
\hline Carmelo Rosales: Lab Activity 2 & 7.33 \\
\hline Venkata Badarla: Lab Activity 3 & 8 \\
\hline Gianvito Lucivero: Lab Activity 4 & 8.86 \\
\hline Francesco Pastorelli: Lab Activity 5 & 8.25 \\
\hline Can Yao: Paper Contest & 8.64 \\
\hline Yannick de Icaza: Paper Contest & 8.14 \\
\hline Nico Mateos & 8.55 \\
\hline Average Global Learning from Questions & \\
\hline
\end{tabular}

Table 1. Extract from the final report of the SWYM,${ }^{8}$ providing the participant's marks.

already interested in science to whom properties of light were presented in this special and attractive fashion. The elementary points were explained with this kind of demonstrations that imitate reality but making it more understandable and amazing. In some occasions questions were asked to the participants of the talk to check whether they had learned what was aimed to be taught. The answers were mostly correct. This was the case in the Summer Workshop for Young Minds, ${ }^{8}$ organized for high school pupils by the ICFO Organization and Network of Stuedents $\left(\mathrm{ICONS}^{9}\right)$. The participants also rated the scientific magic show slightly above other more conventional talks, as seen in Table 1, showing again the power of learning while having fun.

This result encouraged the team to move the performance outside the walls of ICFO. Also with themes related to NLO, the mNACTEC ${ }^{5}$ was reached during a day of 4 conferences about quantum physics and light, giving it the title of "Quantum Physics: Magic of everyday". Then a career guiding activity was promoted in the FME, ${ }^{6}$ in order to propose among mathematics students some professional outputs related to physics. All in the most playful and surprising yet solid manner.

Parallel to this, another line was being developed. Based on the L4H performance, where the main themes were medical prototypes, a new and definitive target was undertaken: to build a show that could appeal all ages and all spirits while giving a glimpse of what light can do for us. Some people who do not work in Optics and Photonics are little aware of the applications that are or will be in their everyday life and would be impossible without the effort done to master light. If a strong support is wanted from the citizens for this area of science it is of capital importance not only to explain the physics research but also, and mainly, the applications involved! Not everybody thinks immediately about smartphones screens, optical fiber communications, medical devices for blood monitoring or laser surgery, microscopy, photovoltaic cells or many others. So here is the idea: introducing optics and photonics through what they enable us to do, presenting it with a powerful dose of illusionism to highlight the fascinating and almost magical devices fabricated.

To achieve the compromise of drawing all kind of public, a balance may be kept between easy understanding explanations and cutting edge advances. Thus the basis of the presentations is still the last prototypes developed at ICFO, so it can interest scientists, and the easy-going kind of performance is also maintained. For this next step a new format was needed as well as the incorporation of Míriam Martí, an outreach professional and trained actress. The final form of this more dynamic talk includes videos, new magic tricks from Carlos Florensa and is now held in an hour. Just enough to take a sip of all three programs of ICFO: Light for Health, Light for Energy and Light for Information. An example is given in Fig. 2.

The first trials for this new setup were made for two groups. Seminari Permanent, ${ }^{10}$ formed by motivated high-school teachers, all of them willing to be well informed of the science advances. And also Aula Senior, ${ }^{11}$ a 


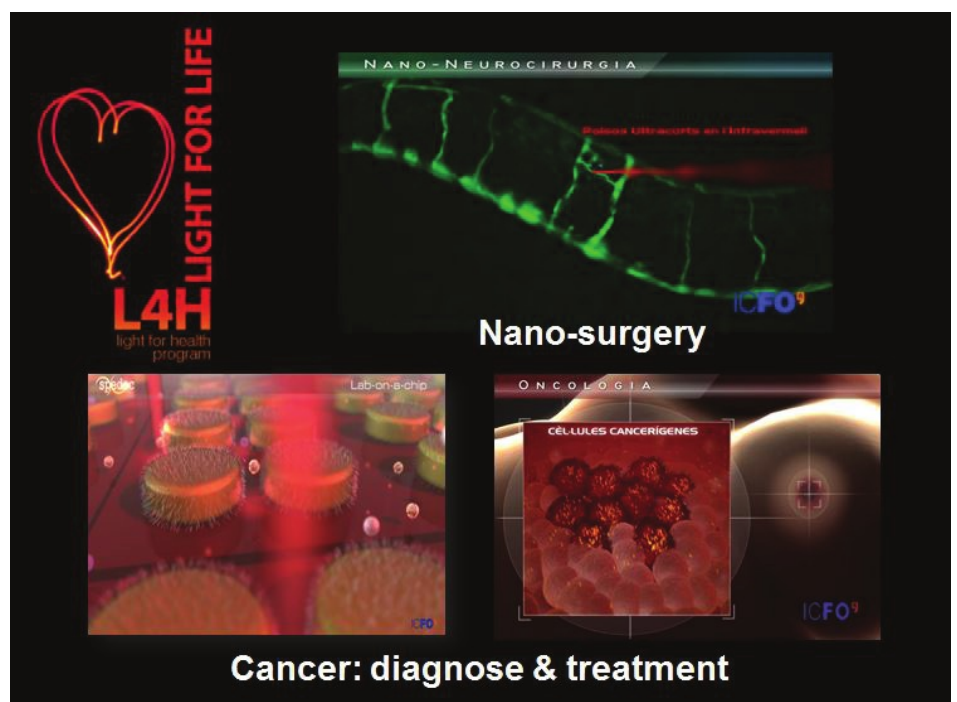

Figure 2. Some of the cutting edge research topics explained in the talk. Light for Health.

group of elder people; in this occasion, a highly valuable comment left by one of the spectators was "This is the first time I deeply enjoy science". This enthusiasm made the project move forward, seeking for other collectives that can be reached with this awareness program.

\subsection{The settlement}

The conference built is highly portable. Wherever there is a projector it can be performed. As for the magic part, it is thought to pack tight and to be scalable from little stands in a science fair as the Big Bang Fair London $^{12}$ (BBF) to large auditoriums as the one in Cosmocaixa. ${ }^{4}$ This allowed the project to reach many places targeting different audiences. Optics and photonics careers were promoted among the youngest in the BBF where we collaborated with the Imperial College ${ }^{13}$ in the stand of the Institute of Physics. ${ }^{14}$ It can be really inspirational for children to hold between their own hands the beam of light that removes an ill cell from an organism. Science gives power, almost magic powers. By enchanting kids with illusions while explaining optics and photonics, a seed is planted containing the desire of knowing more and understanding how it works. This little amazing experience could be one day the gentle wind the student will need to orientate his or her sail towards science. With this in mind, performances have been done for schools and for the high-school pupils of the highly demanding CiMs-Cellex ${ }^{15}$ program on mathematics and sciences.

As mentioned before, transferring scientific activities to general public is of prime importance. And that is why talks were also organized in places accessible to anyone interested, not only the youngest. Some examples are Cosmocaixa and the Cork Museum of Palafrugell. ${ }^{16}$ For the most concurred performances, an effort is made to bring along some of the researchers that have been developing the prototypes we explain. This allows putting in direct contact the audience with the scientists so they can answer themselves and much sharply the questions raised and explain some of the underlying physics not treated in depth during the performance.

\section{ANALYSIS OF THE SUCCESS: FROM SCIENCE ILLUSIONISM TO INSPIRING ALL AGES.}

\subsection{The spectators}

The focus in scientific divulgation talks is, without doubt, the spectators. First of all, it is essential to make them come. A powerful hook is needed. Second, if the final goal is achieved, they have to leave with an expanded knowledge. And something even more important: they have to take with them some inspirational vibes. This is not knowledge, it is emotion. 


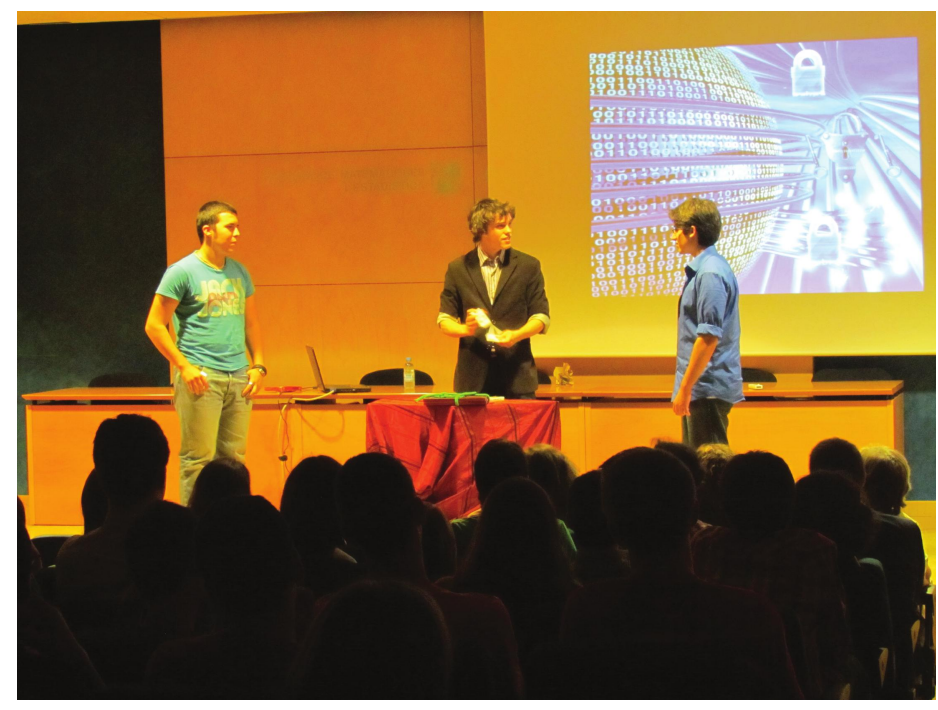

Figure 3. Having the audience involved in the show, during the CiMs-Cellex ${ }^{15}$ talk.

Thus, the contents and the format should be as attractive as possible. The first must inform and raise awareness and the second intend to provide entertainment. Why entertainment? Is it the only way of transmitting science? Not at all. Nevertheless, if the goal is to reach as many different people as possible, there is a need of something that everybody can enjoy: a show. Thanks to this kind of format, a variety of public is attracted, and some of them would never have been appealed by another type of scientific conference. In that way, there were parents coming along with their children, young students not wanting to get bored in a serious talk or even adults not really interested in science but charmed by the idea of performing with it. There is a paradigm shift. Cutting edge science is explored and sharp information is provided about the frontier research, but all in a leisure-like activity where people get surprised, amazed, deceived, involved (see Fig. 3) and, in more general terms, have fun. The aim is to provide such an experience they will remember for a while and even explain to relatives the wonders they witnessed and the science being explained. Studies ${ }^{17}$ suggest that three days after an event, people retain $10 \%$ of what they heard from an oral presentation, $35 \%$ from a visual presentation, and up to $65 \%$ from a visual and oral presentation. Just imagine how much more effective it will be if that visual aid is a magic trick that is not only visual, but engaging and captivating as well. This statement leads to the next section.

\subsection{The synergy}

Is illusionism really a consistent tool to divulgate science? At first sight it does not seem to be so. They even appear to be antithetic. During centuries, magicians have used tricks to make people believe they had superpowers, that they could violate Nature's Laws. And this is clearly not the message we nowadays want to spread. But in fact, with a closer look to those magicians, we discover a common attribute: they often knew more about applied science than their audience! And they used constantly this advantage to deceive the spectators. Particularly interesting is the case of some illusionists of the second half of the XIX ${ }^{\text {th }}$ century, that put chemistry and electromagnetism to the service of their shows. Among them, the watchmaker Jean Eugne Robert-Houdin ${ }^{18}$ cannot be skipped, considering him one of the fathers of modern illusionism. A similar character is Dr. Samuel Cox Hooker, ${ }^{19}$ devoted to chemical research but also creator of one of the most beautiful effects in illusionism.

As said, during centuries, science has been to the service of magicians; but now it is time to return the favor. Magic can indeed be a powerful instrument in science. Some researchers in neuroscience even use prestidigitators to explore how the brain works. ${ }^{20}$ However, let's focus on what concerns the paper: illusionism for divulgation. Analyzing the case, it is found that magic tricks are mainly an intellectual challenge. Exactly what science is by the way! Thus, it keeps the audience awake, with their 5 senses on trying to solve the mystery. This avoids passive attitudes. Furthermore, by daring the spectators' brain and presenting amazing effects related to science, 


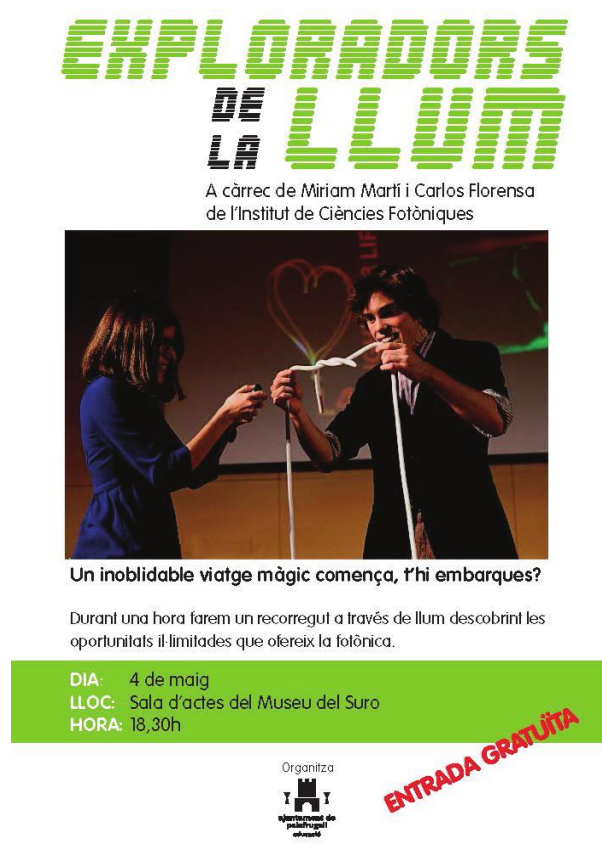

Figure 4. Cutting neurons with a laser pointer in the advertisement of the Cork Museum ${ }^{16}$ act.

a long-lasting record is achieved. Maybe they do not remember that the ultra-violet laser was used to see the fluorescent neurons and the red one to cut them or that regeneration is being investigated after those cuts. But for sure they will remember how with a laser pointer it was mimicked it on stage (see Fig. 4), having a rope cut as many times as desired, and even restored in front of their eyes! The fundamental message is caught and retained: light is capable of doing many useful and different things. During a performance in the Theater of Palafrugell for middle and high-school pupils, it was asked how an ill cell could be found in a living organism. A young student spontaneously answered "With light!".

And the synergy between science and magic does not stop here. Another key property that clearly approaches it to modern science is the magnifying glass effect. In optics and photonics the research dives increasingly in the nano-world, far away from our common perception. This generates the feeling of hard-to-understand science for the general public. And sometimes it is difficult to explain because the behavior of the inhabitants of the nano-world is most of the time odd to people, differing from the macroscopic properties they are used to. Don't know how to tell that light can exert a force? Complicated to clarify quantum effects? Do it with magic! You can get exactly the same strange behavior observable in those cases, but at human size. Illusionism is able to reproduce the impossible and show it in the clearest way. Science coming from the research of the tiniest can be accessible to the wide audience through magic.

It must be said that there are many antecedents to this initiative. A number of scientists or teachers use magic to transmit knowledge in a more captivating and inspiring way. It is easy to learn the basis of this art, just enough to make an efficient use of it in any scientific class or lecture. There are highly recommended references ${ }^{21,22}$ to the ones wishing to introduce themselves to this field. There are even some books dedicated exclusively to illusions with light, ${ }^{23}$ with hints on how to explain the physics behind it. Another option are webpages $^{24,25}$ for gentle learning. A last person that will be mentioned is Martin Gardner, probably one of the most important mathematics divulgator of the $\mathrm{XX}^{\text {th }}$ century. He was also a magician and even wrote a book ${ }^{26}$ about how to teach science through magic tricks. With little effort, the success is granted. Try yourself. 


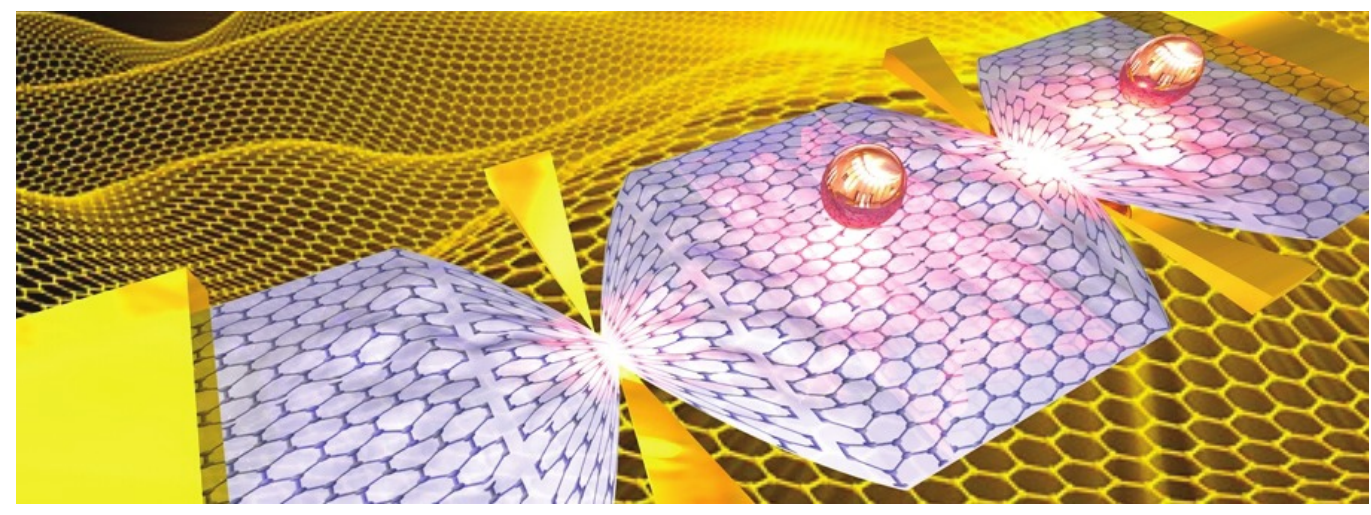

Figure 5. Graphene Plasmonics and nano-photonics: capturing and controlling light at nanometer dimensions (image from http://graphene.icfo.eu/). Being incorporated in the talk.

\subsection{The subsequent}

What comes next? According to one of to the pillars of our show stating that it presents breakthroughs in science, it is deduced that the performance is a live project. It is essential to continuously adapt the contents, keeping it up to date, following closely the research made at ICFO or worldwide. It must transmit how the frontiers of photonics are pushed forward day by day. Thus the performance cannot be decoupled from ICFO or other research center with its warm and active climate. For example, graphene is being added to the talk along with some brushstrokes on its unique properties and its relevance in optoelectronic, see Fig. 5. Then, to create accurate magic effects and to explain to the wide audience where they will find graphene in their future or how does it act exactly, a strong support from the researchers is needed.

Other aspects regarding the future of the project are basically about its expansion. How to reach more people and reinforce the long-lasting effect? Two actions are being implemented. The first one is to create a little school of magic photonics in order to train a reduced number of magicians. The aim is to generate a pool of people with the required skills, both in terms of magic expertise and science divulgation, to present the show. The second idea to strengthen the program is to link it more consistently to a webpage where the audience can share their opinions. This generates also a considerable source of feedback. Furthermore, the projection into the internet dimension can also improve the connection with society through social networks or facilitate the access to further information about the topics treated during the talk.

\section{DISCUSSION AND CONCLUSIONS}

Bring to people cutting edge optics and photonics through magic. Is it the essence of this project? Indeed this particular setup attracts the public and fulfills their expectations with the wonders of light. They come thirsty of surprises and they leave even thirstier of science. Nevertheless, what is really happening is a well-known synergy between outreach activities and the artistic world. Art is probably one of the strongest information transmitters; because it generates a feeling. In this particular case, drama is used. Illusionism belongs to the theater kingdom and is mainly based in the same idea of performance. This outreach activity is worked out so it resembles more a show than a conference, having two Science Communicators interacting with each other as well as with the audience. For inspirational acts, better than just explained, science can be presented as a path to discovery by the hand of the speakers.

From ICFO, the Outreach-KTT Team has other ongoing projects following the same idea. Light Painting in a dark room with a camera and laser beams, audiovisual related programs or even music and poetry in The light on the waves. ${ }^{27}$ Art is a vector. And it can be widely exploited in divulgation. 


\section{ACKNOWLEDGMENTS}

We sincerely thank all the researchers at ICFO that believed in the project and provided valuable help on the contents as well as opportunities for its beginnings. Support by Fundació Cellex Barcelona, Fundació Catalunya - La Pedrera and the Severo Ochoa Program is gratefully acknowledged

\section{REFERENCES}

1. The Institute of Photonic Sciences. http://www.icfo.eu.

2. Outreach- Knowledge and Technology Transfer Team. http://www.outreach.icfo.eu.

3. 50 Years of Non Linear Optics International Symposium, ICFO, ${ }^{1}$ October 2012. http://nlo50.icfo.es/.

4. CosmoCaixa Barcelona Science Museum. http://www.agendacentrosobrasociallacaixa.es/es.

5. Museum of Science and Technology of Catalonia. http://www.mnactec.cat/.

6. Mathematical Faculty and Statistics - UPC Barcelona-Tech University. http://fme.upc.edu/.

7. Light For Health, ICFO, ${ }^{1}$ September 2012. http://www.light4health-icfo.es/.

8. Workshop for Young Minds, ICONS. ${ }^{9}$ http://www.epsyoungminds.org/section/barcelona/index.php?topic=SWYM2012.

9. ICFO Organization and Network of Students. http://www.epsyoungminds.org/section/barcelona/.

10. Seminari Permanent. http://phobos.xtec.cat/cdec/.

11. Aula Senior. http://aulasenior.entitatscastelldefels.cat.

12. Big Bang Fair London. http://www.thebigbangfair.co.uk.

13. Imperial College. http://www3.imperial.ac.uk/.

14. Institute of Physics. http://www.iop.org/.

15. Cims-Cellex program. http://www.cims-cellex.cat/.

16. Cork Museum of Palafrugell. http://www.museudelsuro.cat/.

17. Outreach Program, U.S. Department of Labor. http://www.osha.gov/doc/outreachtraining/htmlfiles/traintec.html.

18. J. E. Robert-Houdin, Essential Robert-Houdin, Tannen, 2000.

19. J. Steinmeyer, "Dr. hooker and the science of marvel," Genii 71, 2008.

20. J. R. A. R. T. J. T. . S. M.-C. Stephen L. Macknik, Mac King, "Attention and awareness in stage magic: turning tricks into research," Nature Reviews Neuroscience $\mathbf{9}, 2008$.

21. J. T. Xuxo Ruiz Domnguez, Educando con magia: El ilusionismo como recurso didáctico, Narcea Ediciones, January 2013.

22. A. J. McCormack, Magic and Showmanship for Teachers, Natl Science Teachers Assn, June 1990.

23. R. Friedhoffer, Light, Scientific Magic Series book 5, Franklin Watts, 1992.

24. http://www.teachbymagic.com/.

25. http://magic.about.com/od/science-magic-tricks/tp/Science-Magic-Tricks.htm.

26. M. Gardner, Martin Gardner's Science Magic, Dover Publications, June 2011.

27. M. Garcia-Matos and S. Carrasco, "Light on the waves - science, music, poetry... and light!," ETOP, 2013. http://lallumalesones.icfo.es/. 